\title{
Influence of Graphite Additives on Mechanical, Tribological, Fire Resistance and Electrical Properties in Polyamide 6
}

\author{
Matyas ANDO
}

\begin{abstract}
New types of polymers are usually produced with different additives. In this work, the effect of graphite addition (1.5wt $\%, 2 w t \%, 2.5 w t \%, 3 w t \%$ and $3.5 w t \%)$ on material's properties is analysed. Results of current investigation show that there are two possible subtypes (groups) of polyamide, containing $2 \%$ and $3.5 \%$ graphite, which reveal improved complex properties. By using graphite additives, the material becomes stiffer. In polyamide- $2 \%$ graphite system, the abrasive wear tends to decrease while the fire resistance improves without significant changes in mechanical properties. In addition to improved tribological and fire resistance behaviour, polyamide with $3.5 \%$ graphite addition gains excellent antistatic properties. At the same time, in this material both the tensile and the Charpy impact strengths have decreased by $15 \%$ and $30 \%$, respectively, whereas the Young's modulus increases by $6 \%$ as a result of dispergation/adhesion between the graphite and polymer.
\end{abstract}

Keywords: electrical behaviours; fire resistance; graphite; magnesium catalysed cast polyamide 6; mechanical-; tribological-;

\section{INTRODUCTION}

Generally, the cast polyamide 6 (PA6) has good mechanical and tribological properties. Traditional PA6 are made by polycondensation process. Researchers have come up with a new approach on casting which is based on the ring opening polymerization. The new casting process has two advantages under production: the process is faster and there is no water secession [1-5]. The sodium catalysed cast PA6 are being extensively used in the semi-finished material production such as bar, tubes, sheets. One of the earlier developments of the PA6 subtypes is the magnesium catalysed cast PA6 that has been used since 1990s. The magnesium catalysed cast PA6 has better impact strength and wear resistance at low load compared with sodium (natrium) catalysed cast PA6 [6]. Due to efficient production, and good behaviour, the cast PA6 is one of the most popular semi-finished engineering materials. In numerous equipment, cast PA6 was used in small- medium series by replacing metal parts, and these parts are generally manufactured using different cutting processes.

There are increasing requirements for special PA6 subtypes in addition to the traditionally used cast PA6. Enhancement of particular property is usually achieved by help of additives. In case of the traditional PA6 one of the most commonly used additives is the graphite. The graphite can be used to reduce the surface resistance [710], but in the case of cast PA6 the literature is limited. In other materials such as epoxy, the graphite additives can reduce the surface resistance until $109 \Omega$. The materials can be subdivided on the basis of surface resistance: antistatic between 1010-1012 $\Omega$, and electrostatic dissipative (ESD) between 106-109 $\Omega[11,12]$. In PA, the graphite additives are traditionally responsible for better wear resistance [1314]. The graphite is well known solid lubricant and widely used in different industrial applications to decrease the friction coefficient [15-18]. The graphite additives can result in better fire behaviour, which is generally not the main aim of the researches so there is only limited information about this effect [19].

Based on the literature the researchers study the effect of graphite additives partially. It is hard to see the complex effect of the additives, because different groups used different base material and different type of graphite. In case of magnesium catalysed cast PA6 (and generally also) there is no information on simultaneous changes in different parameters (mechanical, tribological, electrical, fire behaviour) due to graphite addition.

The aim of this study is to analyse the effect of PA6 behaviour with different graphite content. The goal is to specify the amount of additives, which improve a number of material's properties, suitable for specific applications where pure polymer does not show appropriate performance.

\section{MATERIALS AND METHODS}

The raw material used in the present research is magnesium catalysed cast polyamide 6 (DOCAMID 6G H - Quattroplast Kft., Hungary), whose material properties are shown in Table 1. The CR 5995 graphite was used (Czech Republic), the size of the particles (at least 50\%) are between 5,5-7 $\mu \mathrm{m}$, specific surface area is $10 \mathrm{~m}^{2} / \mathrm{g}$.

Table 1 Magnesium catalysed cast polyamide 6 properties

\begin{tabular}{|l|c|}
\hline \multicolumn{1}{|c|}{ Density } & $1,183 \mathrm{~g} / \mathrm{cm}^{3}$ \\
\hline Young's modulus & $3300 \mathrm{MPa}$ \\
\hline Charpy impact strength & $8 \mathrm{~kJ} / \mathrm{m}^{2}$ \\
\hline Oxygen index (OI) & 22,5 \\
\hline UL-94 category (flammability) & $\mathrm{HB}$ \\
\hline
\end{tabular}

Table 2 Conditions of the mechanical tests

\begin{tabular}{|l|c|c|c|}
\hline \multicolumn{1}{|c|}{ Test } & Standard & Specimen & Test speed \\
\hline Tensile test & ISO 527 & $1 \mathrm{~A}$ & $10 \mathrm{~mm} / \mathrm{min}$ \\
\hline Flexural test & ISO 178 & $60 \times 10 \times 4 \mathrm{~mm}$ & $10 \mathrm{~mm} / \mathrm{min}$ \\
\hline Instrumented impact test & ISO 179 & $1 \mathrm{eA}$ & - \\
\hline Shore-D hardness & ISO 868 & $25 \times 150 \times 5 \mathrm{~mm}$ & - \\
\hline Surface resistance & IEC 60093 & $160 \times 60 \times 60$ & - \\
\hline Abrasive tribological test & ASTM G132 & $\varnothing 8 \times 30 \mathrm{~mm}$ & $80 \mathrm{~mm} / \mathrm{s}$ \\
\hline Fire resistance & UL-94 & $120 \times 10 \times 4$ & - \\
\hline
\end{tabular}

Based on the earlier experiments [20,21], the contents of the graphite additives were the following: $0 \mathrm{wt} \%$ (reference), 1,5 wt \%, $2 \mathrm{wt} \%$, 2,5 wt $\%, 3 \mathrm{wt} \%$ and 3,5 wt $\%$. The test samples were machined from the cast block for the tensile, flexural, Charpy, Shore-D hardness testing and the surface resistance measurement tribological tests and fire 
testing were also performed using the same material (Table 2).

The abrasive tribological test was made in a special test rig corresponding to ASTM G132 standards (pin abrasion tester). The test speed was $80 \mathrm{~mm} / \mathrm{s}$, the surface pressure was $0.7 \mathrm{MPa}$, the abrasive paper was Vitex KK504XP60 and the sliding distance was $5200 \mathrm{~mm}$. The cylindrical test sample has $8 \mathrm{~mm}$ diameter and $30 \mathrm{~mm}$ length. The measuring system comprises the data acquisition to record the forces in 3 directions (friction forces and normal force), moreover, a displacement sensor is separately accommodated for wear measurement. The abrasive test rig is shown in Fig. 1.

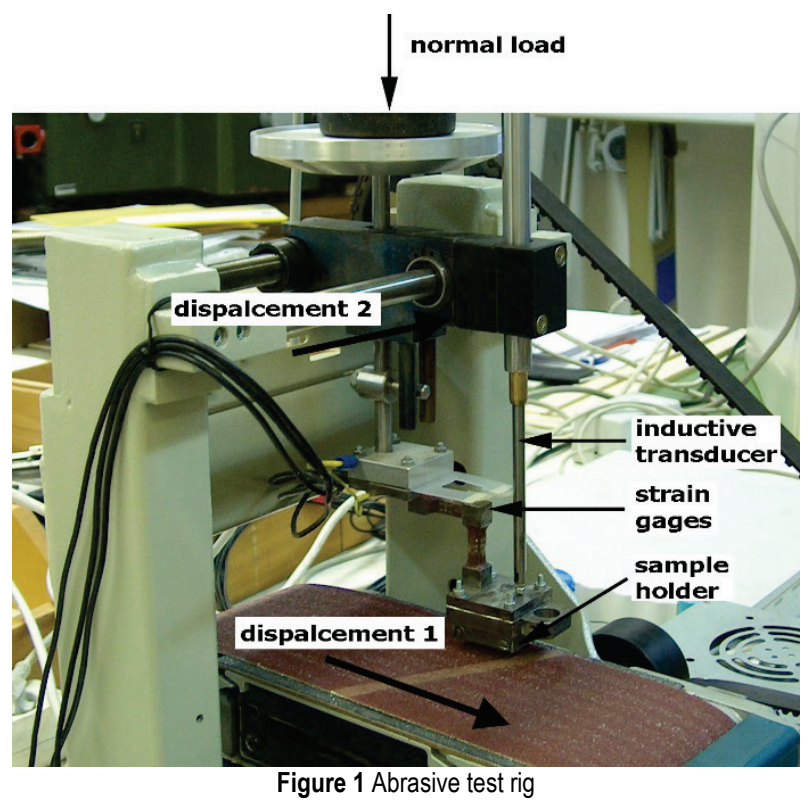

The surface resistance measurement was used to define the antistatic behaviour based on the IEC 60093 standard. Based on the standard, $100 \mathrm{~V}$ was used, which can give surface resistance between $105-2 \times 1011 \Omega$. This range is appropriate, because over $1012 \Omega$ the materials are insulators, whereas for less than $106 \Omega$ they are conductive polymers.

The fire behaviour test was made based on the UL-94 standard, the dimension of the samples was $120 \times 10 \times 4 \mathrm{~mm}$ as shown in Tab. 2. The flammability categories are HB, $\mathrm{V}-2, \mathrm{~V}-1$ and $\mathrm{V}-0$ depends upon the fire performance. HB materials have no fire resistance, and the V-0 materials do not burn in case of fire.

The polyamides can absorb the humidity from air, therefore the samples have to be conditioned. Generally all the measurements were made under dry condition (after casting the samples, they were in an exicator). Only the surface resistivity was measured in 3 different conditions, next to the dry condition (with no water absorption) and normal condition $\left(20^{\circ} \mathrm{C}, 50 \mathrm{RH}\right)$, in wet condition as well (in water at 24 hours). The mechanical tests were carried out with at least 9 samples.

\section{RESULTS AND DISCUSSION}

This section presents the different tests results in order (mechanical, tribological, flammability). In case of the diagrams the error of $\pm 2 \cdot \sigma$, which indicates $95 \%$ probability.

Mechanical characterization was made on the pure polymer and on the polymers with graphite additives (1.5$3.5 \%$ ). The results show that the mechanical properties change linearly. The tensile strength decreases (Fig. 2) as a function of ratio of graphite additives. Tab. 3 shows the average result and the error $( \pm 2 \sigma)$ of the different mechanical properties.

Tab. 4 illustrates the change in mechanical properties because of graphite additives. The table includes the maximum measured difference from the pure material. The table also contains the relative errors, which refer to the repeatability. If the magnitude of the maximum difference and the relative error is the same, then the change is not vital.

Based on the measurements it is clearly seen that small amount of graphite additives (up to $2 \%$ ) cause $5-15 \%$ changes of the mechanical properties. Generally, the graphite additives modify the base material properties, and the new material becomes more rigid. The rigid polymer has increased Young's modulus and flexural strength, however, the tensile strength decreases dramatically. The change in Shore-D hardness is almost negligible. The graphite has significant influence on the dynamic properties, causing a reduction in the Charpy impact strength with a higher rate than that of the change in the other mechanical properties. The variation of the Charpy impact strength with graphite content is shown in Fig. 3, which is over $30 \%$ when the graphite content varies between $0 \%$ and $3.5 \%$. It is also well known that the dynamical test has bigger errors, almost $8 \%$ in the test under discussion.

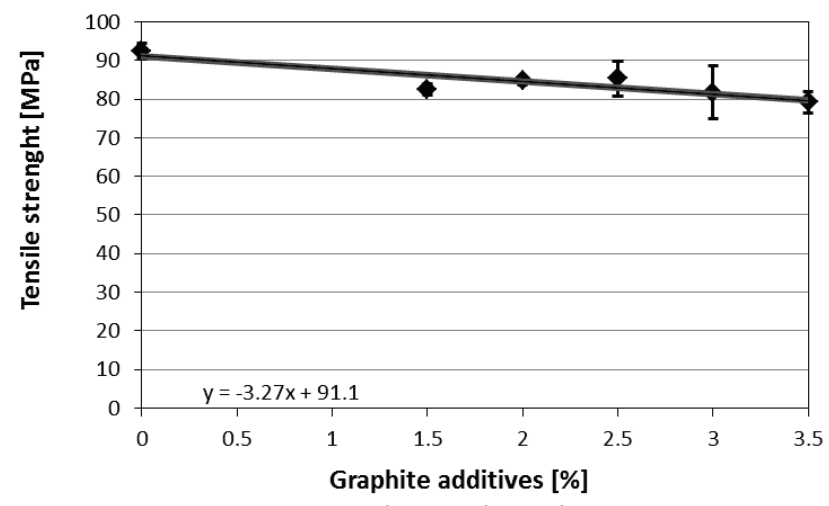

Figure 2 Tensile strength as function of ratio of graphite additives

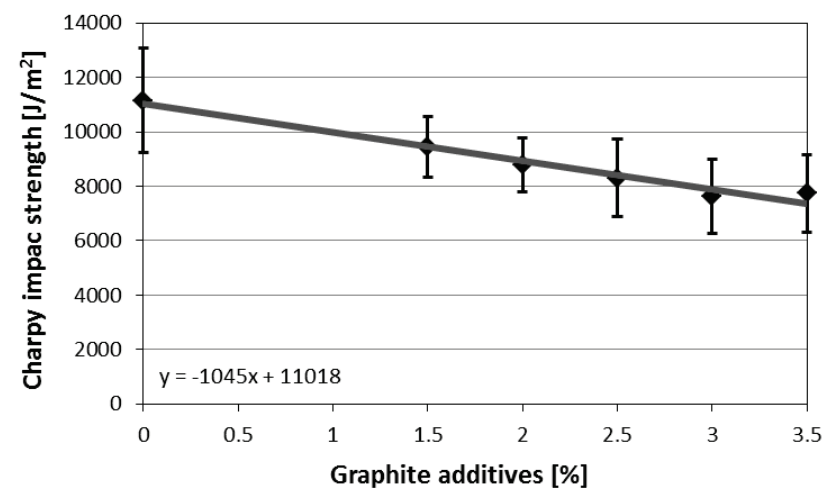

Figure 3 Charpy impact strength as function of the graphite content 
Clearly seen are the graphite particles on the fractured surface after Charpy test, which means that there is no strong adhesion between the original base material and the additives (Fig. 4). The cracks can grow much faster next to the graphite particles without strong adhesion, which leads to smaller Charpy impact strength. Consequently, increasing graphite content gives decreasing impact strength.

Table 3 Result of the mechanical tests

\begin{tabular}{|c|c|c|c|c|c|c|}
\hline Mechanical properties & $0 \%$ & $1.5 \%$ & $2 \%$ & $2.5 \%$ & $3 \%$ & $3.5 \%$ \\
\hline Young's modulus (tensile) (MPa) & $2018 \pm 133$ & $2040 \pm 94$ & $1968 \pm 55$ & $2018 \pm 89$ & $2095 \pm 69$ & $2103 \pm 71$ \\
\hline Tensile strength (MPa) & $92 \pm 2.0$ & $82 \pm 1.3$ & $85 \pm 1.0$ & $85 \pm 4.4$ & $82 \pm 6.8$ & $79 \pm 2.7$ \\
\hline Flexural modulus (MPa) & $2896 \pm 92$ & $3067 \pm 174$ & $3140 \pm 101$ & $3284 \pm 179$ & $3319 \pm 203$ & $3161 \pm 175$ \\
\hline Charpy impact strength $\left(\mathrm{J} / \mathrm{m}^{2}\right)$ & $11511 \pm 1926$ & $9440 \pm 1100$ & $8793 \pm 987$ & $8293 \pm 1424$ & $7636 \pm 1360$ & $7736 \pm 1433$ \\
\hline Shore-D hardness (-) & $84.5 \pm 0.5$ & $82.5 \pm 1.0$ & $82.4 \pm 0.7$ & $83.3 \pm 0.8$ & $82.7 \pm 2.2$ & $83.6 \pm 0.3$ \\
\hline
\end{tabular}

Table 4 Effect of the additives on the mechanical properties

\begin{tabular}{|l|c|c|c|}
\hline \multicolumn{1}{|c|}{ Mechanical properties } & Equation for the fitted curve & Max. difference (\%) & 6.4 \\
\hline Young's modulus (tensile) $(\mathrm{MPa})$ & $22.3 x+1996$ & 14.4 & 3.3 \\
\hline Tensile strength $(\mathrm{MPa})$ & $-3.27 x+91.1$ & 12.2 & 4.1 \\
\hline Flexural modulus $(\mathrm{MPa})$ & $98.3 x+2923$ & 32.8 & 2.6 \\
\hline Charpy impact strength $\left(\mathrm{J} / \mathrm{m}^{2}\right)$ & $-1045 x+11018$ & 2.4 & 7.9 \\
\hline Shore-D hardness $(-)$ & $-0.31 x+83.8$ & 1.3 & \\
\hline
\end{tabular}

The graphite additives have very clear effect on the tribological properties. A small amount of graphite additives is sufficient to reduce the abrasive wear intensity. From $1.5 \%$ of graphite the wear intensity is reduced by $25 \%$ (Fig. 5.), which can significantly improve the lifetime of the machined parts. Higher graphite content cannot lead to better tribological properties. In practice, the minimum amount is recommended, which makes it more competitive than other solid lubricants.

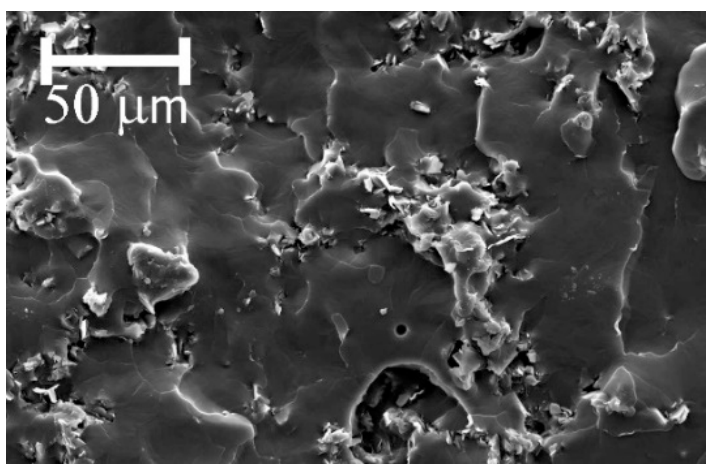

Figure 4 Fractured surface of PA- $2 \%$ graphite
Apart from wear intensity, the friction coefficient also decreases by $8-10 \%$ for polymers with graphite additives, having tendencies similar to abrasive wear. Thanks to the two effects, the energy balance of the operation and the extended lifetime $(33 \%)$ are requirements in case of abrasive environment like bearing, cam, ways application at mines, agricultural machines and excavators.

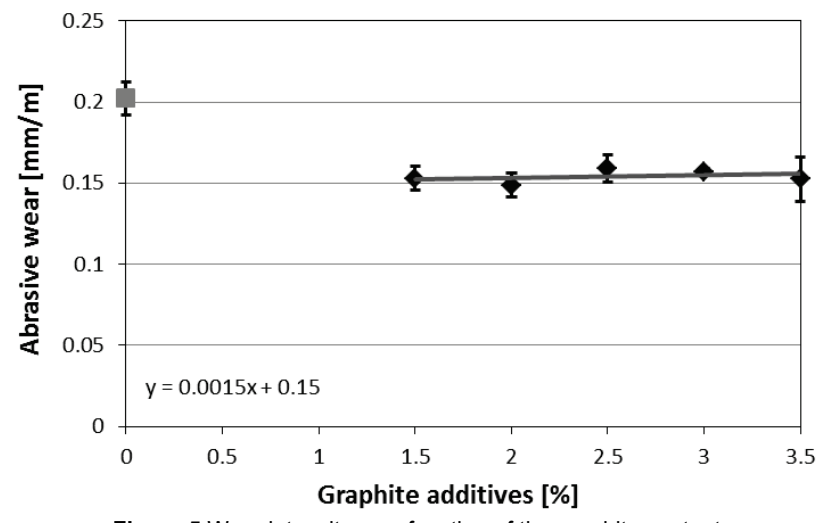

Figure 5 Wear intensity as a function of the graphite content

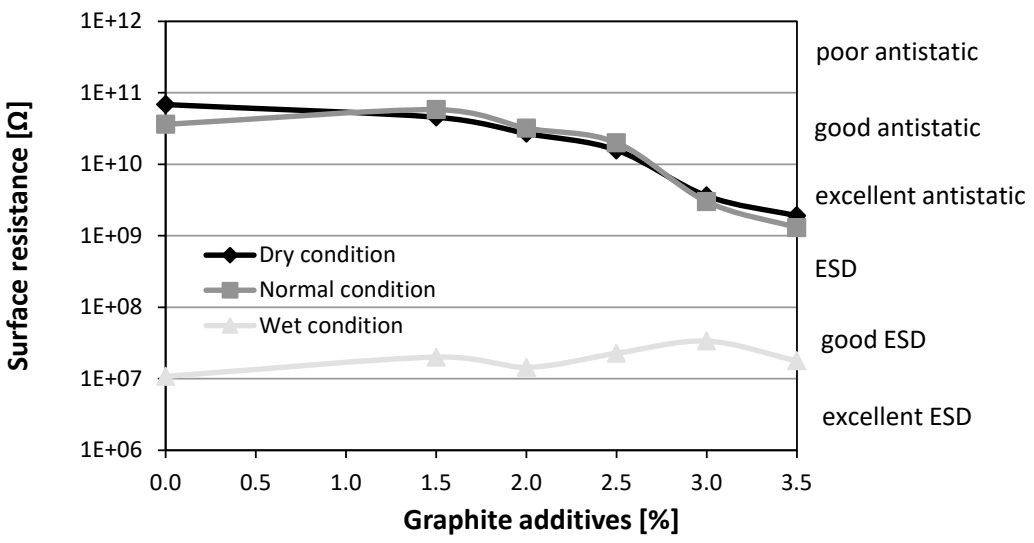

Figure 6 Surface resistance as function of the graphite content

Originally, the diverse polyamides are insulator materials, but with the additive, they gain good antistatic properties. Fig. 6 shows the result of the surface resistivity measurement at the three different conditions. More than $2.5 \%$ additives are needed to achieve excellent antistatic properties at dry and normal conditions. More additives further decrease the surface resistivity, which means that the material has better antistatic properties.

In Fig. 6 it is obvious that there is no big difference between the dry and normal conditions, which are the most typical application conditions. The graphite particle, which has good electrical conductivity, is on the base matrix 
(PA6), and more additives lead to get smaller distance between the graphite particles. If the distance is decreasing linearly, the surface resistance also decreases, but with increasing intensity. At wet condition, the PA6 absorbs water at the top layer of the surface. In this layer, the electrical charges can move much easier. In wet condition more graphite additives cannot improve the electrical behaviour $(107 \Omega)$, because the absorbed water originally responds to the requirement of better conductivity.

The flammability was also studied on these samples. The results of the UL-94 test are in Tab. 5.

Table 5 Fire behaviour function of the graphite content

\begin{tabular}{|c|c|c|}
\hline $\begin{array}{c}\text { Graphite } \\
\text { contents (\%) }\end{array}$ & $\begin{array}{c}\text { Mark of the } \\
\text { group }\end{array}$ & Comments \\
\hline 0 & HB & dropping every 2 sec \\
\hline 1.5 & V-2 & stop burning after dropping \\
\hline 2 & V-2 & stop burning after dropping \\
\hline 2.5 & V-2 & stop burning after dropping \\
\hline 3 & V-2 & stop burning after dropping \\
\hline
\end{tabular}

The pure polyamide is dropping during the burning process. The graphite additives cannot modify this behaviour, however more energy is needed to create the fire (more time is required). After lighting the fire, the dropping behaviour ensues with the melt drop, and thus a substantial part of the energy is dissipated from the burning system. A relatively smaller energy is not enough to sustain the fire and consequently the samples stop burning. Although the samples cannot burn along the measuring section, the dropping can spread the fire for the environment, which means that the samples cannot be in a flammability category better than V-2.

\section{EVALUATION}

Relying only on the mechanical test results, it is hard to decide which additive content can be efficient. At first relative values were calculated, based on the pure material properties. The relative flexural modulus was calculated by the following Eq. (1):

$$
\operatorname{rel} E_{\mathrm{g}} \%=\frac{E_{0} \%}{E_{0} \%}
$$

where the $E_{0} \%$ is the flexural modulus of the pure material, the $E_{\mathrm{g}} \%$ is the flexural modulus of the samples with graphite additives. The results of the calculation are shown in Fig. 7.

Table 6 Factorization of mechanical properties for two different applications

\begin{tabular}{|l|c|c|}
\hline \multicolumn{1}{|c|}{ Mechanical properties } & $\begin{array}{c}\text { Agricultural } \\
\text { sliding bearing }\end{array}$ & $\begin{array}{c}\text { Holder in an } \\
\text { assembly tool }\end{array}$ \\
\hline Young's modulus (tensile) $(E Y)$ & 0.1 & 0.3 \\
\hline Tensile strength $(\sigma)$ & 0.0 & 0.2 \\
\hline Flexural modulus $(E F)$ & 0.3 & 0.2 \\
\hline Charpy impact strength $(C)$ & 0.3 & 0.2 \\
\hline Shore-D hardness $(S)$ & 0.3 & 0.1 \\
\hline Summa & 1.0 & 1.0 \\
\hline
\end{tabular}

For all results from mechanical tests, relative values were defined and calculated similarly. In order to evaluate the results, the relative values are added to each other to obtain a general tendency. The importance of the mechanical parameters is related to the application where the material will be used. Tab. 6 contains two possible factorizations (where sums should be 1) for two different engineering applications.

Suitable calculation for the application can be made based on the factors. For example, in case of holder (2):

$$
\begin{aligned}
& \operatorname{relM}_{\mathrm{g}} \%=0.3 \cdot \operatorname{relEY} \%+0.2 \cdot \operatorname{rel} \sigma_{\mathrm{g}} \%+ \\
& +0.2 \cdot \operatorname{relEF} F_{\mathrm{g}} \%+0.2 \cdot C_{\mathrm{g}} \%+0.1 \cdot S_{\mathrm{g}} \%
\end{aligned}
$$

where $r e l M_{\mathrm{g}} \%$ is the relative mechanical properties for different values of graphite content. The results of the calculation are provided in Fig. 8.

Based on the calculation there is no vital difference according to the factorization. Although the factors are significantly different the mechanical properties exhibit limited changes. Generally, the material becomes stiffer with graphite additives, which gives little lower values. Generally, the relative mechanical properties decreased with a maximum of $5 \%$. These changes cannot limit the traditional applications of the polyamide 6 .

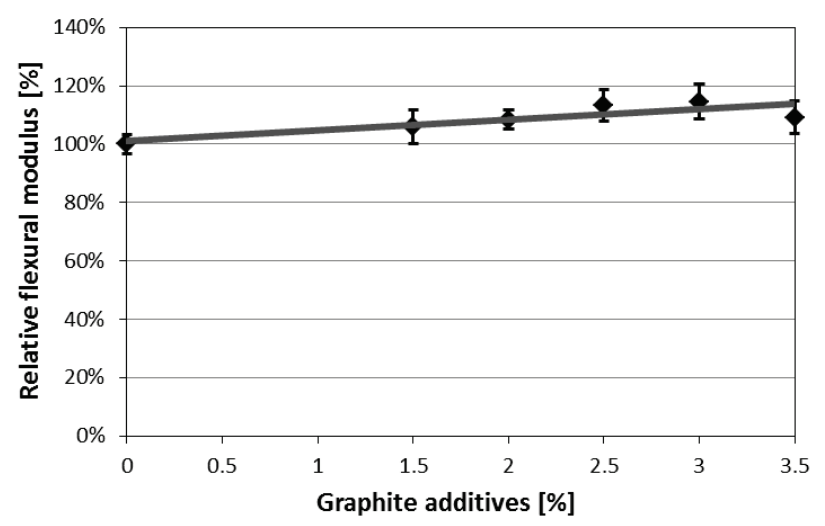

Figure 7 Relative flexural modulus as function of the graphite content

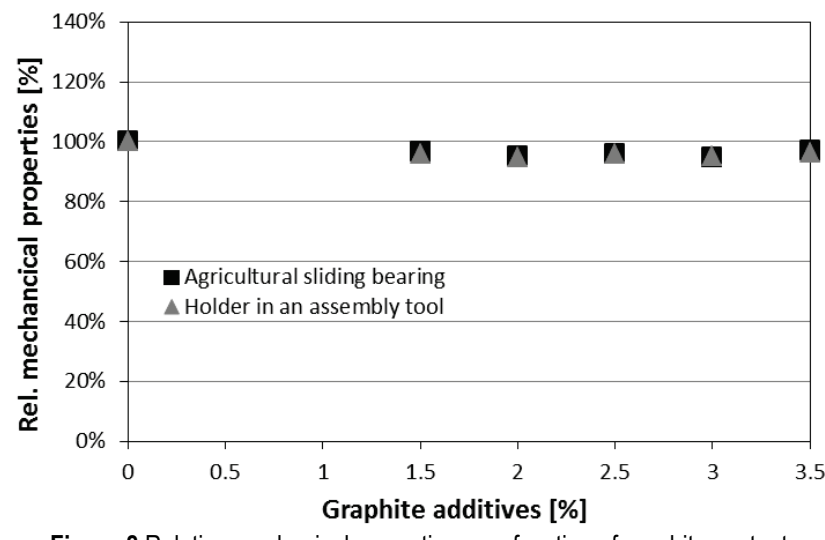

Figure 8 Relative mechanical properties as a function of graphite content

Table 7 Factors for the different application in case of different properties

\begin{tabular}{|l|c|c|}
\hline \multicolumn{1}{|c|}{ Properties } & $\begin{array}{c}\text { Agricultural sliding } \\
\text { bearing }\end{array}$ & $\begin{array}{c}\text { Holder in an } \\
\text { assembly tool }\end{array}$ \\
\hline Mechanical properties & 0.2 & 0.5 \\
\hline Tribological properties & 0.5 & 0.2 \\
\hline Electrical properties & 0.2 & 0.2 \\
\hline Fire behavior & 0.1 & 0.1 \\
\hline Summa & 1.0 & 1.0 \\
\hline
\end{tabular}

Based on material development, the target properties were the antistatic behaviour, better tribology and the better fire resistance. By applying the same mathematical 
method we can compare the different additives (Tab. 7 and Fig. 9).

Based on the calculation it is clearly seen that for the two kinds of application using graphite additives gives better properties. For example, in an agricultural sliding bearing the tribological properties mean the most important factor, which justifies using $1.5 \%$ graphite additive. At $1.5 \%$ the value of relative material properties is $122 \%$, whereas at $3.5 \%$ this value increases to $130 \%$. The last value becomes greater due to the great antistatic behaviour, which can also increase the bearing lifetime (less dust on the bearing surface). In case of the holder the relative values are smaller, but still greater than $100 \%$. This application traditionally depends upon the mechanical properties, which do not change dramatically. In case of this application the wear resistance and the antistatic properties also have influence on the operation and maintenance (no charging effect, easier to clean).

The additives change the material properties, but the measurements are not comparable mathematically. Using the relative values and the factorization, better material can be chosen based on the numbers and not on the intuition. These two examples showed the method of the calculation. If the engineers/researchers know the application field, then they can choose the correct factors.

\section{CONCLUSION}

In the newly developed magnesium catalysed cast polyamide 6 (PA6), the graphite additives improve the tribological, electrical and fire behaviour. Fig. 10 shows the relative changes in case of different properties. The change in mechanical properties is closely linear, while the other properties show complex trends.

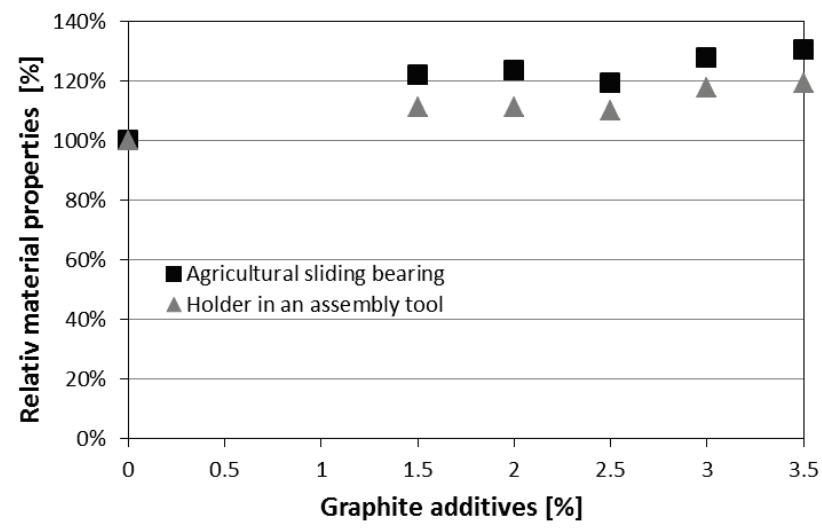

Figure 9 Relative material properties as a function of graphite content

The abrasive wear decreased by $25 \%$. The PA6 inhibits excellent antistatic properties in case of 3\% of graphite additives. The flammability is better from $1.5 \%$ additives, $\mathrm{V}-2$ category is better than the original HB. Moreover, the mechanical properties also change the stiffness of pure PA6 increases due to the graphite additives. The flexural strength increases by $10 \%$ but the Charpy impact strengths and tensile strengths decrease by $30 \%$ and $15 \%$ respectively.

Based on this study, $1.5 \%$ graphite additive is sufficient to provide better tribological, fire and electrical properties without losing much of the mechanical strengths. $1.5 \%$ additives cannot limit the original application range but provide extra application fields. With $3 \%$ of graphite additives, the samples become antistatic. The fire and tribological properties remain the same as those of $1.5 \%$ additives. At $3 \%$ the sample becomes more rigid, the Charpy impact strength decreases by $30 \%$. An application range has been narrowed due to the rigid behaviour; however, the composition can be used in new applications, because of the improved antistatic properties.

\section{Realtive tendencies}

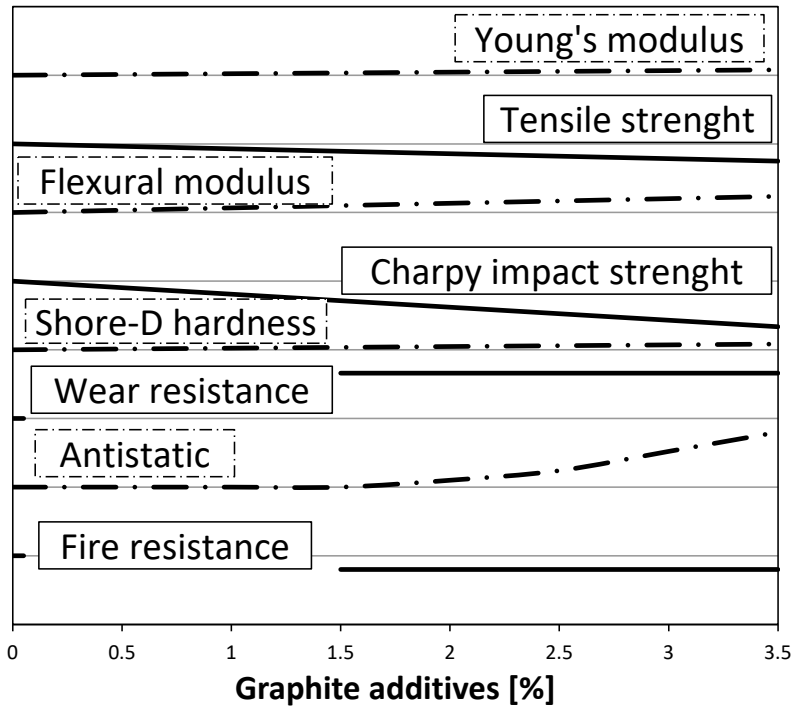

Figure 10 Relative tendencies of different properties

The relative values help to choose the optimal additive content for the specific application. In case of agricultural bearing $1.5 \%$ graphite additive is sufficient to get $20 \%$ better material; $3.5 \%$ additive can provide $30 \%$ relatively better material properties than those of pure PA6.

\section{REFERENCES}

[1] Kaiser, W. (2007). Kunststoffchemie für Ingenieure (2. auflage), Carl Hanser Verlag München, 347-363.

[2] Brydson J. A. (1999). Plastics Materials ( $7^{\text {th }}$ Edition), Elsevier, 478-530. https://doi.org/10.1016/B978-075064132-6/50059-0

[3] Chanda, M. \& Roy, S. K. (2007). Plastics Technology Handbook (4 ${ }^{\text {th }}$ Edition), Taylor \& Francis Group, 71-79.

[4] Yang, M., Gao, Y., He, J. P., Li, H. M. (2007). Preparation of polyamide 6/silica nanocomposites from silica surface initiated ring-opening anionic polymerization. eXPRESS Polymer Letters, 1, 433-442. https://doi.org/10.3144/expresspolymlett.2007.61

[5] Kalacska, G. (2013). An engineering approach to dry friction behaviour of numerous engineering plastics with respect to the mechanical properties. eXPRESS Polymer Letters, 7, 199-210. https://doi.org/10.3144/expresspolymlett.2013.18

[6] Samyn, P., De Baets, P., Schoukens, G., \& Van Driessche, I. (2007). Friction, wear and transfer of pure and internally lubricated cast polyamides at various testing scales. Wear, 262, 1433-1449. https://doi.org/10.1016/..wear.2007.01.013

[7] Markarian, J. (2008). New developments in antistatic and conductive additives. Plastics Additives \& Compounding, 10, 22-25. https://doi.org/10.1016/S1464-391X(08)70172-7

[8] Novák, I. \& Krupa, I. (2004). Electro-conductive resins filled with graphite for casting applications. European Polymer Journal, 40, 1417-1422. https://doi.org/10.1016/j.eurpolymi.2004.01.033 
[9] Li, J. H., Feng, L. L., \& Jia, Z. X. (2005). Preparation of expanded graphite with $160 \mu \mathrm{m}$ mesh of fine flake graphite. Materials Letters, 60, 746-749. https://doi.org/10.1016/j.matlet.2005.10.004

[10] Zheng, W., Lu, X. H., Wong, S. C. (2004). Electrical and mechanical properties of expanded graphite-reinforced highdensity polyethylene. Journal of Applied Polymer Science, 91, 2781-2788. https://doi.org/10.1002/app.13460

[11] Bruyne, D. (1998). ERTA Engineering Plastics. 3P Engineering Workshop. Seminar booklet. Tielt, Belgium.

[12] Varis, J. (2001). Static dissipative compounds: solutions for static control. Plastics Additives \& Compounding, 3, 16-19. https://doi.org/10.1016/S1464-391X(01)80249-X

[13] Chang, L., Zhang, Z., Zhang, H., \& Schlarb, A. (2006). On the sliding wear of nanoparticle filled polyamide 66 composites. Composites Science and Technology, 66, 31883198. https://doi.org/10.1016/j.compscitech.2005.02.021

[14] Arjula, S. \& Harsha, A. (2006). Study of erosion efficiency of polymers and polymer composites. Polymer Testing, 25, 188-196. https://doi.org/10.1016/j.polymertesting.2005.10.009

[15] Li, D., Xie, Y., Li, W, You, Y, \& Deng, X. (2013). Tribological and mechanical behaviors of polyamide 6/glass fiber composite filled with various solid lubricants. The Scientific World Journal, Article number 320837. https://doi.org/10.1155/2013/320837

[16] Deng, X., Li, D.-X., Wang, J., \& Yang, J. (2012). Polyamide 6/polyurethane/graphite composites prepared by anionic polymerization process. II. Friction and Wear. Advanced Materials Research, 532-533, 30-34. https://doi.org/10.4028/www.scientific.net/AMR.532-533.30

[17] Unal, H. \& Mimaroglu, A. (2012). Friction and wear performance of polyamide 6 and graphite and wax polyamide 6 composites under dry sliding conditions. Wear, 289, 132-137. https://doi.org/10.1016/j.wear.2012.04.004

[18] Du-Xin, L., Wen-Juan, L., Ying, X., \& Xiang-Xiang, L. (2012). Effects of solid lubricants on friction and wear behaviors of polyamide 6. Journal of Applied Polymer Science, 124, 4239-4248. https://doi.org/10.1002/app.35409

[19] Uhl, F. M., Yao, Q., Nakajima, H., Maniasc, E., \& Wilkie, C. A. (2005). Expandable graphite/polyamide-6 nanocomposites. Polymer Degradation and Stability, 89, 7084. https://doi.org/10.1016/j.polymdegradstab.2005.01.004

[20] Ando, M., Kalacska, G., \& Czigany, T. (2008). Cast Polyamide 6 Polymer Composites for Special Application. $14^{\text {th }}$ "Building Services, Mechanical and Building Industry days" International Conference, 30-31 October 2008, Debrecen, Hungary, 296-303.

[21] Andó, M., Kalácska, G., \& Czigány, T. (2008). Cast Polyamide 6 Polymer Composites for Agricultural Machine Applications. Hungarian Agricultural Engineering, Gödöllö, 67-69.

\section{Contact information:}

Matyas ANDO, PhD, Associate Professor

Savaria Institute of Technology,

Faculty of Natural Sciences and Technology,

University of West Hungary,

Karolyi Gaspar ter 4., H-9700 Szombathely, Hungary

ando.matyas@nyme.hu 